\title{
Consultório na Rua e Redução de Danos: estratégias de ampliação da vida
}

Street Clinic and Harm Reduction: strategies for increasing life

Consultório en la calle y reducción de daños: estratégias para extender la vida

Deidvid de Abreu ${ }^{\mathrm{a}}$

A atenção à saúde da população em situação de rua (PSR) tornou-se alvo de inúmeros estudos e pesquisas. Nesse contexto, diferentes experiências têm sido colocadas em cena, principalmente aquelas relacionadas às equipes de saúde da família para a PSR, ao Programa de Saúde da Família (PSF) sem domicílio, ao Consultório de Rua, e da mais recente estratégia da Política de Atenção Básica direcionada à PSR, o Consultório na Rua. Estas ações buscam incluir a PSR nas ofertas de cuidado e atenção integral em saúde. Por sua vez, isto tem requerido certa desenvoltura dos profissionais de saúde para perceber, compreender e intervir a partir das singularidades desse grupo populacional, ampliando suas práticas para além do costumeiramente atendido no Sistema Único de Saúde (SUS).

Como aponta o artigo "Vivência em Consultório na Rua do Rio de Janeiro: a situação de rua sob uma nova perspectiva", ${ }^{1}$ a experiência de conhecer e se aproximar da PSR pode potencializar um senso de humanidade, muitas vezes precário ou mesmo ausente em muitas práticas de saúde. O autor apresenta a complexidade do cuidado a esta população, que numa perspectiva intersetorial, compreende a garantia mínima de saúde, habitação, trabalho, alimentação, documentação, educação, participação e de serem reconhecidos como sujeitos de direitos.

Nesse sentido, o artigo traz sensivelmente a Redução de Danos (RD) e a medicina centrada na pessoa como partes fundamentais de um cuidado integral e respeitoso a vida e ao contexto social das pessoas em situação de rua. Práticas estas que devem estar presentes no cotidiano dos todos os profissionais que atuam no contexto da saúde.

Obstante a RD, o autor sinaliza que seu texto tem a finalidade de esclarecer como o Consultório na Rua utiliza-se desta para melhorar o cuidado à PSR. Durante a escrita, o autor não deixa clara esta questão, apresentando apenas os benefícios da RD na relação com o uso de drogas ao sinalizar a possível minimização de riscos

Fonte de financiamento: declaram não haver.

Parecer CEP: não se aplica. Conflito de interesses: declaram não haver. Procedência e revisão por pares: revisado por pares. Recebido em: 19/12/2016. Aprovado em: 30/12/2016. 
biológicos, sociais e econômicos. A RD é muito mais, compreende um olhar singular sobre o contexto do sujeito e a construção de experimentos únicos e pensados sempre na relação com o mesmo.

Ela compreende estratégias práticas de reflexão sobre o consumo de água/alimentação, uso de preservativos e outras práticas de cuidado com a saúde. Nesse sentido a RD torna-se uma estratégia de ampliação da vida, ${ }^{2}$ pois além de trabalhar questões relacionadas ao uso de drogas e à saúde geral, também busca sensibilizar à PSR para participação e engajamento, tanto no autocuidado em saúde quanto na vida social, principalmente no seu reconhecimento como sujeito de direito. ${ }^{3}$

Outro aspecto que o autor poderia ter explorado de forma mais consistente foi a negação de atendimento à PSR justificada por muitos profissionais de saúde pela falta de documentação pessoal. Cabe destacar que nenhuma pessoa, indiferente de classe, gênero, etnia e/ou condição social pode deixar de ser atendida no SUS por falta de documentação e ou/Cartão Nacional de Saúde (CNS), conforme descreve a Portaria do Ministério da Saúde no 940/2011. ${ }^{4}$ Esta portaria afirma que não será condicionada a confecção de CNS à PSR exigindo-se comprovação de residência, já que tal exigência mostra-se contraditória ao contexto de vida desta população e ao princípio da equidade, tão importante na atenção às diferenças no âmbito do SUS.

Por estas lentes, que miram a partir da estratégia da RD de forma ampliada e atuam na defesa da atenção à saúde de todos, sem exceção, o Consultório na Rua constitui-se como uma excelente e desafiante estratégia de garantias de direitos. Dispositivo que convida diferentes profissionais para o exercício da inclusão social e equidade, objetivos estes capazes de contribuir na transformação da vida e experiência da PSR.

\section{Referências}

1. Camargo BP. Vivência em Consultório na Rua do Rio de Janeiro: a situação de rua sob uma nova perspectiva. Rev Bras Med Fam Comunidade. 2016;11(38):1-3. DOI: http://dx.doi.org/10.5712/rbmfc11(38)1269.

2. Lancetti A. Clínica Peripatética. 6a ed. São Paulo: Hucitec; 2011.

3. Brasil. Presidência da República. Decreto n. 7.053, de 23 de dezembro de 2009. Institui a Política Nacional para a População em Situação de Rua e seu Comitê Intersetorial de Acompanhamento e Monitoramento, e dá outras providências. [acesso 2017 Jan 19]. Disponível em: http://www.planalto.gov.br/ccivil_03/_Ato2007-2010/2009/Decreto/D7053.htm

4. Brasil. Ministério da Saúde. Secretaria de Atenção à Saúde. Portaria no. 940, de 28 de abril de 2011. Regulamenta o Sistema Cartão Nacional de Saúde (Sistema Cartão). [acesso 2017 Jan 19]. Disponível em: http://conselho.saude.gov. br/legislacao/docs/portaria_940_cartaoSUS.pdf

${ }^{a}$ Hospital Universitário Polydoro Ernani de São Thiago (HU/UFSC). Florianópolis, SC, Brasil. abreuddd@gmail.com (Autor correspondente) 